have tried I think Valium is the only drug which has some peripheral effect without affecting too much the general condition of the patient. However, the trouble with all these drugs is that they act as soon as one starts them but the action wears off after a more or less short time because the human organism becomes accustomed to them. Therefore, if one has to increase the doses there is always the danger that the patient becomes addicted. This is also the reason why we do not use analgesics in the acute stages of traumatic paraplegia, and drugs like morphia, etc., have been absolutely taboo at the Stoke Mandeville Centre since its inception. Under proper supervision in spinal units the prescription of drugs of any kind can be cut down to a minimum. However, we found that some practitioners are indiscriminate in the prescription of these drugs, as Michaelis has pointed out correctly, to quieten themselves and consequently some patients returned to us as drug addicts.

Walsh, $\mathscr{F} \cdot \mathcal{F}$. (England). I am quite convinced that in one or two certainly incomplete spastic lesions Valium has been really effective in small doses. With regard to other effects of Valium I recently had a case-an old patient of ours-who was sent to me in some distress because his engagement had been broken off, and when I had gone into the question of it this was entirely due to deterioration in sexual function. He then admitted that he was taking quite large doses of Valium (not prescribed by us). We stopped this with good results but he came back about a week later crying out for Valium. $\mathrm{He}$ said he must have it-he could not go on. When I asked him why, he said that the spasms were so much worse and so on, but in fact they were not, and I think he had a drug addiction to Valium.

$M c$ Sweeney, $T$. (England). On the question of Valium, of which I have very little experience, I suspect strongly that it is the first cousin of Librium, which is being used extensively in mental hospitals and which, I regret to say, we use in elderly people with fractures of the femoral neck. It is a house surgeon's sedative which like all sedatives, leads to addiction.

\title{
ANTERIOR RHIZOTOMY FOR THE RELIEF OF SPASTICITY
}

\author{
By A. SutCliffe KerR, F.R.C.S. \\ Walton Hospital, Liverpool
}

Following the Atlantic Charter of the Four Freedoms promulgated by Roosevelt and Churchill during World War II, Donald Munro (I945) produced his Charter of the Four Facilities for Paraplegic Patients, in his article in the New England Fournal of Medicine.

Doubtless most of you will remember his vivid phraseology-'If he has been properly treated, every patient with a spinal cord or cauda equina injury, who is intelligent and co-operative, and has the use of the shoulder, arm and hand muscles, can be made ambulatory; can have such control of the bladder and bowels as to sleep through the night without either getting up or wetting himself (and) can carry out ordinary activities throughout the day without soiling himself with faeces or having to evacuate his bladder oftener than once every three hours; can lead a normal social life, and . . . can earn a satisfactory living.'

For those days, when little advance had been made in the management of paraplegia compared with the gloomy and hopeless attitude adopted generally 
through the I920s and I930s, these claims were revolutionary in their concept and produced a profound reaction in the attitude of our profession to the whole problem of paraplegia.

Of course, Donald Munro was not unique in his role as protagonist for a completely new conception of the possibilities still open for a paraplegic patient for, contemporaneously in this country, our own Sir Ludwig Guttmann had already established his Spinal Injury Centre here and, with a dynamic intensity of purpose, had already proven and even extended the range of the Four Facilities of Donald Munro.

My purpose in this brief historical retrospection is to draw your attention to the fact that Munro regarded the control of spasticity in paraplegic patients as being of such importance that his article has as its first subtitle, the phrase: ' $I$. Anterior Rhizotomy for Spastic Paraplegia'.

It is not my purpose to try to justify Munro's elevation of this procedure to such an important place in the hierarchy of treatments, nor even to claim that it is necessarily superior to other methods of prevention or treatment, but merely to remind you that it can be a useful (and even life-saving) procedure in certain circumstances.

The criteria which I have adopted for recommendation to the patient that he should submit to the procedure are:

I. That he has a complete lesion of the spinal cord with intractable spasticity, or that, as for example in cases in demyelising lesions of the spinal cord, the degree and duration of spasticity are such as to outweigh completely any remaining voluntary control of leg muscles; such as to constitute a danger to life from incipient or established pressure sores; or such as to render life intolerable from the frequency and severity of spasms.

2. That the function of the urinary bladder is sufficiently satisfactory for it to be important not to interfere with the spinal reflex arc subserved through the lower sacral nerve roots and the conus medullaris.

In this latter connection, I have also thought it wise to preserve muscular tone and reflex activity in the abdominal muscles (even when they were involved in the undesirable excessive spasms) so as not to interfere with the auxiliary muscles of micturition which help to reduce any residual urine to a minimum.

For this reason I have departed from the original recommendation of Munro (I945), and later supported by Freeman and Heimberger (I947), that the anterior nerve roots from the Ioth or I Ith thoracic to the Ist sacral segments should be divided, and content myself with dividing those from the I2th thoracic (or even Ist lumbar) to the Ist sacral segments inclusive. This means that the laminectomy undertaken is of the Ist and 2nd lumbar vertebrae instead of the IIth and I2th thoracic as recommended by Munro, or the I2th thoracic and Ist lumbar, by Freeman and Heimberger.

In an adult, the conus medullaris invariably ends at a point within a centimetre of the middle of the body of the 2 nd lumbar vertebra and it can easily be identified after opening the dura mater and arachnoid, as it lies in the midline between the roots of the cauda equina.

All the posterior nerve roots and the conus medullaris are gently retracted to one side, thereby displaying the anterior nerve roots to the lower lumbar and saclar $\mathrm{L}$ 
segments and the combined anterior and posterior nerve roots, as they run to the intervertebral foramina at $\mathrm{L}_{1} / \mathrm{L}_{2}$ and $\mathrm{L}_{2} / \mathrm{L}_{3}$. (fig. I). Throughout the remainder of the procedure, the ist lumbar nerve root (issuing through the $\mathrm{L}_{\mathrm{I}} / \mathrm{L}_{2}$ foramen) is used as the main point of orientation and all counts are checked by reference back to it.

It is easy to define the separate anterior and posterior nerve roots of $\mathrm{L}_{\mathrm{I}}$ at the intervertebral foramen and the former of the two is picked up on a black silk thread passed around the nerve on a small aneurysm needle. A similar procedure follows for L2 and the anterior nerve roots alone are then defined and picked up in the same way from $\mathrm{L}_{3}$ to $\mathrm{S}_{\mathrm{I}}$ inclusive. (fig. 2) Almost invariably the next lower nerve root $\left(\mathrm{S}_{2}\right)$, which is not touched, is the largest in diameter of all the nerve roots. Rarely this distinction may fall to the SI nerve root, but one must check and double check if this does seem to be the case, since one of the major justifications for the procedure of anterior rhizotomy is the fact that it is possible to control spasticity without altering bladder reflex activity.

Having defined each nerve root, they are stimulated one by one by a very weak diathermy current. A muscular reaction can be observed and the identity of the nerve root confirmed. A strong coagulating current is then applied and each nerve root is cut.

Exactly the same procedure follows on the opposite side, and the dura mater is then sutured and the wound closed in two layers.

Following the operation, each leg should be flaccid from the groin to the buttocks, but the lower abdominal muscles should retain their normal tone. As a general rule we have found that distressing involuntary spasms disappear from the abdomen because the flaccidity of the legs prevents the start of the usual 'massreflex' type of reaction to any stimulus. A few patients have continued to complain of discomfort because of involuntary abdominal contractions, but we have tried to encourage them to tolerate this in order to avoid possible deterioration in bladder emptying with the danger of developing a higher residual urine.

In one or two such cases, we have performed a high thoracic anterior lateral tractomy of the spinal cord with satisfactory pain relief.

Munro (1945) first undertook the operation in 1933, and he reported the results in I9 cases in 1945, and Freeman and Heimberger (1947) added 28 further cases ( 15 of their own) with good results in 26 and no deaths.

The first case in my series was operated upon in October 1945, and the second and third were also operated upon before the Spinal Injuries Unit was established in Southport in 1947. There was then a long gap until 1953 before I judged that further suitable cases were arising-probably because various other methods of relief had been given a trial before reverting to the more definitive therapy of anterior root section. A further hiatus has occurred during the past i 2 months since Dr. Silver took over the charge of the Unit, and during this period alternative methods are again being tried and assessed.

Altogether the operation has been undertaken on 30 cases between 1945 and I965. Nineteen of these were due to trauma above the level of the Ioth thoracic segment ( 2 due to gunshot wounds) and the remaining II had various conditions (8 disseminated sclerosis, I T.B. cord, I spinal tumour and I thoracic disc lesion) (Table I).

Spasticity had been present for periods varying from 3 months up to 20 years 


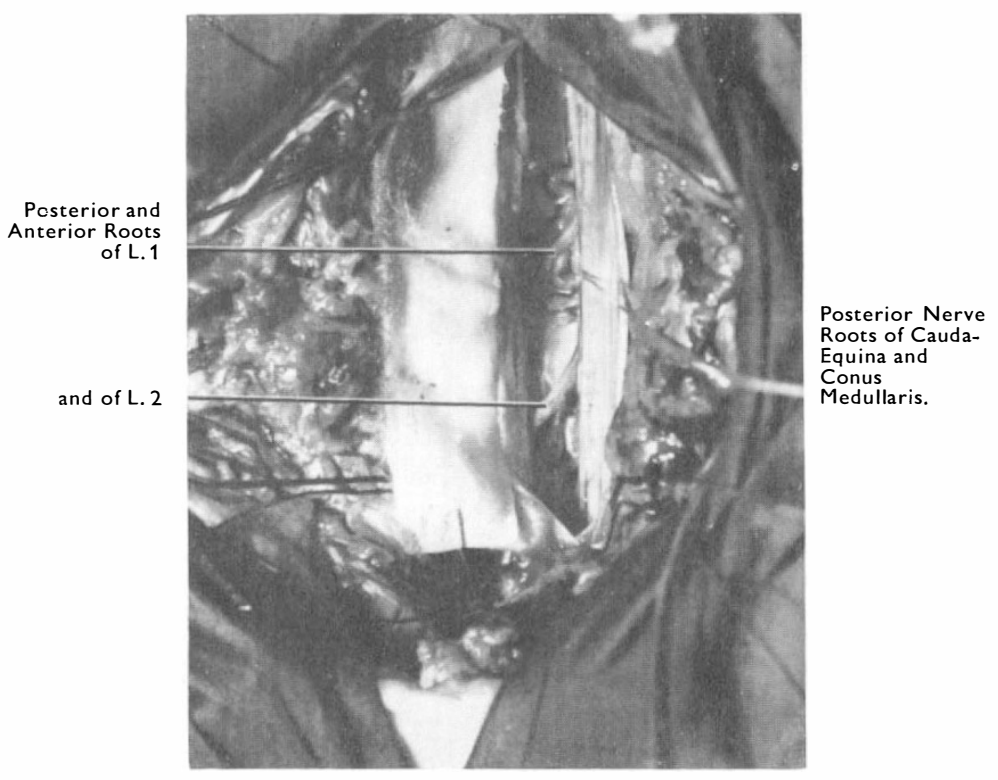

FIG. I

Laminectomy of Ist and 2nd lumbar vertebrae.

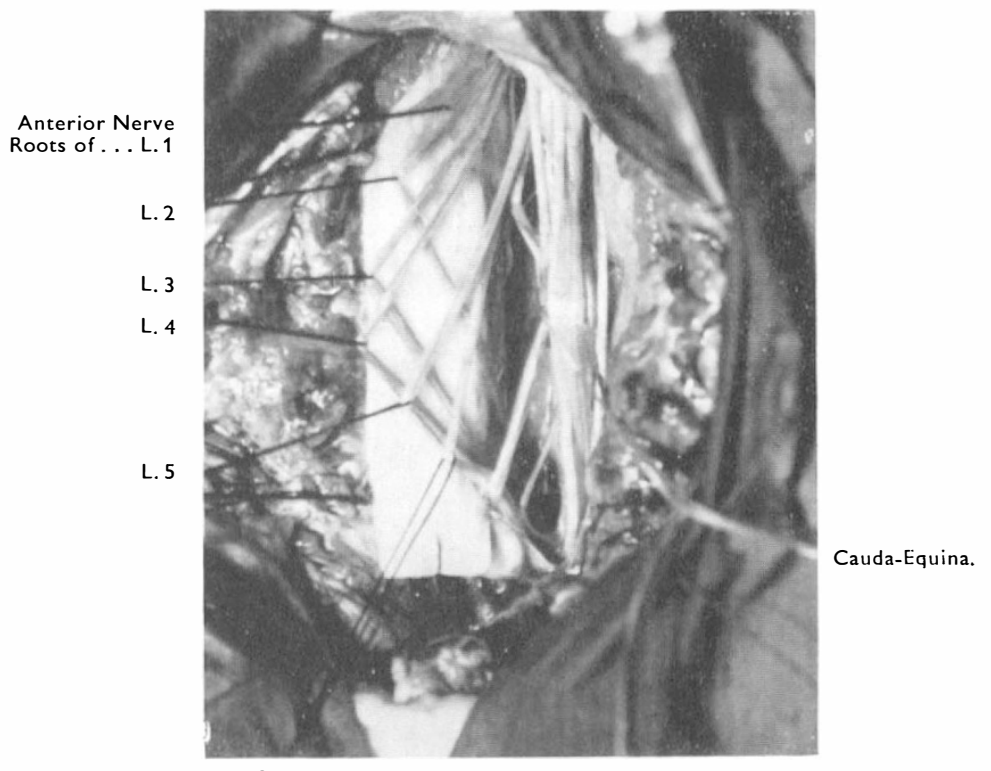

FIG. 2

Anterior nerve roots individually retracted before division. 
and had invariably led to difficulty in management, either of avoiding pressure sores or treating them, and had often been associated with the development of joint contractures.

\section{TABLE I}

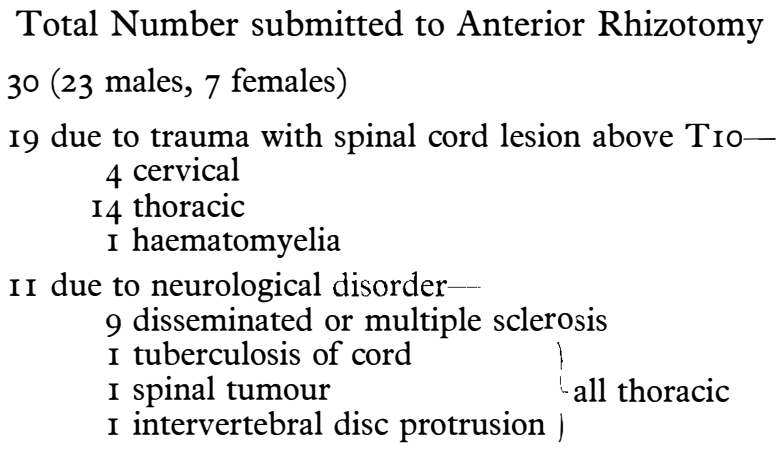

In all cases, the spasticity was more or less completely relieved in the legs and I have, therefore, classified the results to show the general effect upon the patient (Table II) because the operation may be indicated in a patient who is desperately ill from extensive pressure sores or urinary infection, or who has intolerable suffering from frequent spasms and yet may be in good general condition.

\section{TABLE II}

General Effect upon the Patient. 30 Cases

\begin{tabular}{|c|c|c|c|}
\hline Excellent & $V$. good & Good & Improved \\
\hline $\begin{array}{l}\text { Complete relief. } \\
\text { Healing of } \\
\text { pressure sores. }\end{array}$ & $\begin{array}{l}\text { Almost complete } \\
\text { relief. Healing } \\
\text { of sores. }\end{array}$ & $\begin{array}{l}\text { Abdominal } \\
\text { spasms.. Sores } \\
\text { slow to heal. }\end{array}$ & $\begin{array}{l}\text { Relief of dis- } \\
\text { comfort. Sores } \\
\text { intractable. } \\
\text { Contractures. }\end{array}$ \\
\hline
\end{tabular}

$\begin{array}{lllll}4 & 7 & \text { I3 } & 5 & \text { I }\end{array}$

The operation may still be well worth while for the subjective relief given to the patient, even though his or her expectation of life may be limited. As will be seen from the table, we felt that only one patient failed to benefit from the procedure. She was a case of disseminated sclerosis with established joint contractures and deep pressure sores over the hip. Subsequently she has had to have an amputation by disarticulation through the hip.

Table III shows the effect upon the urinary bladder. In only three cases was there any harmful effect upon urinary bladder function, and two of these occurred in 1945 when the section was carried higher and when our genito-urinary colleagues had less experience in the management of the paralysed bladder. One does not claim any beneficial effects upon bladder function so that established infection and other problems still need genito-urinary treatment, and the development of late complications is only to be expected in a few cases.

One of the major indications for abolishing spasticity of the legs is to assist in the avoidance and the treatment of pressure sores (Table IV). Only in I4 out of the 30 cases were we successful in either avoiding or in healing completely sores 
already present, but there was a very marked improvement in eight further cases, and only three failed to improve or continued to deteriorate. Of the five who developed sores later (and probably some of the eight still liable to superficial breakdown) it is possible to argue that an important factor in this problem is the loss of bulk of the denervated muscles. With a reasonably co-operative patient, however, we have never found these late and superficial sores to be a serious problem.

TABLE III

Effect on Urinary Bladder Function. 30 Cases
No effect
Compared with
pre-operative
function.

23

Weak expulsion

Deterioration

Late complications

(Calculi

hydronephrosis)

I

(both in 1945 cases)

TABLE IV

Effect on Pressure Sores. 30 Cases

No sores

before or

after.
No improvement or worse.

4
Sores

healed.

7
Much improved Developed late but liable to (muscular superficial atrophy). breakdown.

The fact that 9 out of the 30 patients have died (Table V) seems, at first sight, to be a rather high proportion but it will be noted that the only relatively early deaths were in cases of neurological disorder and explicable on grounds other than those of spasticity, while the other deaths were not greater in number than one would anticipate from a group of spinal injuries during the past 20 years.

TABLE V

30 Cases. 9 Deaths

I Spinal tumour died within 8 months from date of onset.

I Disseminated sclerosis died within 2 years.

I Disseminated sclerosis died within 18 years.

I Cervical lesion died within 5 years.

I Cervical lesion died within I3 years.

I Thoracic lesion died within 5 years.

I Thoracic lesion died within 8 years.

I Thoracic lesion died within ro years.

I Thoracic lesion died within 20 years.

In brief, therefore, I would suggest that bilateral anterior rhizotomy of the nerve roots from $\mathrm{TI}_{2}$ or $\mathrm{LI}_{\mathrm{I}}$ to $\mathrm{S}_{\mathrm{I}}$ inclusive, is a useful method of combatting intractable spasticity after thoracic or cervical cord lesions, particularly when 
relatively satisfactory control of urinary bladder function has been established, and when it is important not to risk damage to the spinal reflex arc. In order to assist emptying of the bladder, the Ioth and I Ith thoracic nerve roots should not be cut even if they subserve some degree of spasticity because this is rarely a problem once the flaccidity of the legs prevents the development of the full mass reflex.

If spasticity cannot be controlled by preventive measures and by physiotherapy and fails to respond to drugs such as myanesin or valium, then destructive measures must be contemplated. Of these, anterior rhizotomy is the only one which offers accurate control and certain avoidance of damage to the urinary bladder reflex arc.

\section{SUMMARY}

Donald Munro in I933 first undertook the procedure of anterior rhizotomy for the relief of spasticity in cases of thoracic cord injury and reported his results in 1945 .

The present series comprises 30 patients since that date, but the procedure has been modified slightly so as to avoid cutting the nerve roots to the lower abdominal muscles.

The main justification for the procedure is the avoidance of any interference with the reflex arc for control of the urinary bladder and it would appear appropriate also to leave the lower abdominal reflex muscular activity intact so as to encourage full emptying of the bladder.

\section{REFERENCES}

Freeman, L. W. \& Heimberger, R. F. (1947). F. Neurosurg. 4, 435. Munro, D. (1945). New Engl. F. Med. 233, 453.

\section{Discussion}

Ascoli (Italy). I was very interested in the paper of Mr. Sutcliffe Kerr. I am not a neuro-surgeon, but I have heard that they execute at the same time section of anterior and posterior root. I should like to know if anyone has had experience of this matter of section of both anterior and posterior roots and what are the results.

Sutcliffe Kerr, A. (England). No, I did not cut any posterior nerve roots, I felt it very important that one should not cut the posterior nerve roots in order to preserve sensation of the skin. My operations concerned bilateral anterior nerve roots from TI2 to $S_{I}$ inclusive. But I do want to stress that the rhizotomy is reserved for these patients who have spasticity but who also have satisfactory bladder function and it is vital not to interfere with it. And I do not think that any other destructive procedure, whether it be phenol or alcohol, can achieve that degree of certainty.

Sir Ludwig Guttmann. I am glad you made it quite clear that you reserve anterior root section for those cases where the bladder function is satisfactory. That means, in cases above the lumbar segments where the spinal bladder centre is intact and the patient has a satisfactory automatic bladder. May I ask you a question here. As you know, there is a very large vessel in LI on either side and it is a fact that if, during operation, these vessels, especially bilateral, are severed, then the result is profound disturbance of the bladder, i.e. the automatic bladder is transformed into an autonomous bladder. Have you observed this too? Furthermore, I would have liked if you could have shown us the cystometrographic findings before and after the anterior root sections. That is quite 
important now as people make claims about preserving bladder function. I think in future every case should be shown with an exact physiological investigation of the bladder before and after operation and also the time of observations if the bladder function is disturbed. I would be glad if Mr. Sutcliffe Kerr could enlighten us about the vascular supply and the effect of transection of the vessels in $L_{I}$.

Sutcliffe Kerr. With regard to the question of the large vessel which goes along the first lumbar nerve root, it is generally present, but my experience has been it nearly always ascends to the cord by the posterior nerve root, and I leave the posterior root intact, and the anterior nerve root has never in my experience had the large vessel upon it. Therefore, I do not think there is any fear that one would seriously jeopardise the vascular supply to the conus medullaris. I did in my table No. 3 try to give a picture of what we had assessed the urinary bladder function as being pre- and post-operatively, and I did ask my colleague .Mr. Norman Gibbons if he would join me in presenting this paper. When I did so, he wrote back and said there was no need for him to come. He had seen all the cases. I cannot give you chapter and verse, and I do not think he has done detailed cystometric studies on all the cases, but his assessment was that 23 out of 30 showed no change compared with pre-operative function.

Sir Ludwig Guttmann. The second question I want to ask Mr. Kerr is this: He quite rightly mentioned spasms of abdominal muscles in some of his cases, and that sometimes the spasms are even increased. This is often a problem in higher lesions say at the level of T 5 and cervical lesions, and, from what Mr. Kerr told us, in certain cases another laminectomy was necessary. I think one has to ask here whether two laminectomies in a traumatic paraplegic are a good thing with regard to his posture. We have to consider that by further diminishing the stability of the spine we interfere with the posture of these patients.

Another point: There is a certain group of patients with higher thoracic lesions who have rhythmic contractions of the erector spinae, and the patient's life can become very miserable by continuous extensor spasms of the whole body. I would like to ask Mr. Kerr whether he has seen this kind of case and what he would suggest to do in these cases.

Sutcliffe Kerr. First of all I would say that as far as laminectomy undertaken by a surgeon in a non-damaged area is concerned there is no weakening of the spinal stability whatsoever. We only take off the lamina and the spine, we do not touch the articulations laterally, the pedicles are intact, the discs are intact, and the spine is as stable after operation as it is before. But I do agree that it is undesirable to go indiscriminately doing laminectomies here and there, and I said it was either one or two patients upon whom a antero-lateral cordotomy had been done for the relief of pain.

I cannot say that I have ever seen intractable extensor spasms affecting the erector spinae, and as far as the abdominal muscles are concerned, again I think I made it clear that the relief of the spasticity of the legs is followed by complete cessation in some cases or nearly complete cessation of the abdominal reflex activity in the majority of cases.

Sir Ludwig Guttmann. Of course, we can have the same effect with alcohol block in these high lesions. In fact, I demonstrated a number of cases of cervical lesions where the elimination of spasticity from the lower part of the body has a very beneficial effect on the spasticity of the upper limbs.

Harris, $P$. (Scotland). I would like to support Mr. Kerr in his indications for anterior rhizotomy. There is just one point I would like to make at this time. I think a cystometrogram during operation is quite useful in helping to assess which roots are going to be divided.

Could I make one other point in the discussion we have had today on spasticity. We have covered so many aspects of physiology right through the medical and surgical forms of treatment of spasticity. It is the question of terminology. I think we are using certain terms rather loosely: we are talking about spasticity, spasms, rigidity, contractures 
and deformities. I think we might pay close attention to the use of these terms in our deliberations; for example, in cervical lesions one can see spasticity and certainly contractures without any spasticity, and you can see contractures even with lower neurone lesions.

\section{FOLLOW-UP OF A SERIES OF PHENOL SPINAL BLOCKS}

By Dr. E. Apolinario, M.D., Dr. J. C. Dominelli, M.D., Dr. M. Fernandez, M.D. and Dr. F. Sotelano, M.D.

National Rehabilitation Centre, Buenos Aires, Argentina

THE interference of spasticity upon urinary tract function and activities of daily living has led us to use intrathecal phenol blocks for therapeutic purposes in a group of spinal patients.

Our present report is a follow up of those I5 patients who were reported at the 1965 meeting of the International Medical Society of Paraplegia (Table). Results were evaluated according to neurological, urological findings, performance of A.D.L. and bioelectrical findings.

(a) Neurological Findings. The myotatic reflexes belonging to the area of injected nerve roots were absent $\mathrm{I} \frac{1}{2}$ years after the block.

The polysynaptic reflexes were completely abolished in most cases, only a few showed a weak reflex response on plantar stimulation and a persisting Babinsky sign. Effects upon muscle power and sensation could not be tested because most of the patients had complete lesions.

(b) Urological Findings. In patients who were catheter free prior to the block there was no loss of bladder control. Frequency of micturition was unchanged. Those who had an interrupted urine stream because of spasms gained a free micturition after blocking. In only one case the residual urine was increased and an indwelling catheter had to be inserted. In this patient bladder sensation was also lost.

(c) Performance of Activities of Daily Living. This improved a great deal. Patients had no longer any difficulty in dressing the lower limbs and transferring in and out of bed, wheelchair and car was easily achieved.

(d) Bioelectrical Findings. Electromyography of the muscles corresponding to blocked areas showed complete absence of electrical activity, either at rest or on stimulation. The non-affected muscles showed a lesser degree of activity than that obtained in the previous records.

\section{RESULTS}

Abolishment of spasticity in order to obtain a better functional ability was achieved and remained permanent.

As was to be expected, spasticity in non-blocked areas had to be treated with other procedures: tenotomies in five cases, peripheral nerve block in one case, and phenol spinal block of the opposite side in another one. 